\title{
Recommendations: The Federal Depository Library Program and Title 44
}

\section{Excerpts from response to ALA-WO and COL from GODORT: August 31, 2017}

\section{GODORT's FDLP / Title 44 Prin-}

ciples are recommendations that seek to strengthen the promise of long-term access to federal information by building on the existing strengths of the Federal Depository Library Program (FDLP). These Principles focus on Chapter 19 but also address policy codified in other parts of Title 44, including Chapters 17, 35 , and 41.

We see the majority of these Principles as supportive of activities authorized under current law, and in many cases already underway as part of existing GPO initiatives. If there is an opportunity to strengthen and clarify these provisions, we believe it is the best interest to do so.

\section{Summary: FDLP / Title 44 Principles}

1. Permanent no-fee public access to federal information can be accomplished through continued partnership between GPO and libraries.

a. Update the definition of "government publication."

b. Guarantee free access and privacy protections for users of federal information.

c. Improve GPO's ability to partner with depository libraries.

d. Maintain the regional-selective depository model with minor changes.

2. The FDLP is well-positioned to play a significant role in the long-term preservation of federal information.

a. Make all information dissemination products managed by GPO available to collect and preserve. b. Create a role for depository libraries to accept deposit of digital federal information.

3. Improvements to broader federal information policy will facilitate better access and more reliable preservation.

\section{Details: FDLP / Title 44 Principles}

1. Permanent no-fee public access to federal information can be accomplished through continued partnership between GPO and libraries.

The core strength of the Federal Depository Library Program (FDLP) is that it is a network of libraries of all types, including academic, law, public, federal, and state libraries, working individually and in partnership with GPO and other program participants to accomplish the broad goal of ensuring public access to federal government information in all formats. The changes we have identified will strengthen the network and modernize the scope of its purview to reflect changes in how the government informs the public.

We note that any privatization of federal government information dissemination or preservation is antithetical to the public right to access this information, and would also reduce the costeffectiveness of the current system in providing access to federal information for agencies and departments.

1.a. Update the definition of "government publication."

The scope of Chapter 19 should be updated to include information, regardless of form or format, that a federal agency publishes, discloses, disseminates, or makes available to the public. This change reflects the ways in which government informs the public, and makes clear the government's responsibility to ensure access to this information. This expanded definition would be interpretable to include audio and video content, databases, information from FOIA reading rooms, and other means of public information dissemination used by federal departments and agencies.

Records under the purview of NARA continue to be as such; this update addresses only public information, and reflects the government's responsibility to ensure long-term access to all of its information dissemination products.

1.b. Guarantee free access and privacy protections for users of federal information.

While GPO does not currently use its Chapter 41 authorization to charge fees for access to its digital repository outside of depository libraries, this outdated provision stands in opposition to the mandate to provide public access. All digital products, including ebooks and databases, and their accompanying metadata should be freely available to access and download, and not subject to cost recovery under Chapter 17.

GPO's online tools and services are subject to the same privacy protections in place for other federal web services, a fact that can be clarified in its governing authority. To further protect user privacy, users should be notified of any web tracking that is essential 
for the functionality of the tools and databases, and have the option to opt out or leave the website. These privacy measures are in alignment with ALA's Bill of Rights (see: http://www.ala.org /advocacy/intfreedom/librarybill/interp retations/privacy).

1.c. Improve GPO's ability to partner with depository libraries.

Depository libraries create metadata, digital surrogates, training tools, and other valuable resources on a daily basis. Currently, the law does not permit GPO to accept this content and incorporate it into its systems without providing something of value in exchange. Providing GPO with gift authority will enable the agency to set standards to ingest metadata and digital surrogates created by partner libraries into its repository without the current quid pro quo requirement. This provision will help partnerships between GPO and depository libraries to result in expanded public access.

While retention does not ensure preservation, it is the basis for all preservation activities. GPO's coordination of retention agreements in its existing FIPNet preservation stewardship program could be enhanced with grants or in-kind support, particularly for description and conservation for print documents. Giving GPO grant-making authority would provide the agency leverage to work to balance inequities in existing practices.

1.d. Maintain the regional-selective depository model with minor changes.

The principle at the heart of the FDLP is simple: sharing responsibilities across a network of libraries accomplishes what a single government agency or library alone cannot. Regional depository libraries have agreed to permanently retain their collections for the benefit of all selective depository libraries, other libraries in their district and state, and the general public within their state. They also ensure the appropriate disposition of government publications, which are public property, through oversight of the discard process. Both of these responsibilities are foundational to the effectiveness of the distributed network. Regional depository libraries also play a crucial role by providing guidance and other forms of support to libraries within their state, along with reference and interlibrary loan services.

Opportunities exist for regional and selective depositories to collaboratively manage collections and provide services across state lines. When doing so fills an identified gap in the network, the FDLP should be able to accommodate multi-state and shared regionals, and other forms of regional arrangements across state lines. Given that one of the strengths of the regional depository system is the service relationship between each regional and the selective depository libraries within their jurisdiction, any multi-state arrangement should be subject to the approval of a majority of depository libraries affected by the arrangement. These arrangements must also be subject to senatorial approval.

The relationships between Congress and the libraries designated by members of Congress as depositories are crucial to Congressional support for the program. With that said, the limitations of no more than two regionals per state, and the minimum collection size of 10,000 volumes, are no longer justified in defining the program parameters and needlessly limit participation. The number of regionals can be increased per state to make it possible for libraries to share the work of retention, preservation, and reference services; and any library willing and able to provide information services to the public should have the opportunity to participate in the program.

Additionally, it is in the best interest of the program to keep the designation of law libraries as a special category in order to encourage their participation. Depository libraries should be able to select any print format published by an agency, including bound and unbound publications, in order to best serve their users.

Libraries that do not accept or manage print or digital collections still do important work in enabling and enhancing access to government information within their communities of service. However, it is misleading to refer to these libraries as depositories, as they are not receiving anything on deposit. Another FDLP participant category would better reflect these roles.

2. The FDLP is well-positioned to play a significant role in the long-term preservation of federal information.

Permanent public access requires a preservation strategy. In addition to ensuring access, the decentralized nature of the FDLP lends itself to fulfilling long-term preservation of federal information dissemination products. Many depository libraries have already undertaken preservation as part of their depository responsibilities, including conservation and description work. Chapter 19 should be amended to formally authorize GPO to assist in the preservation of federal government information to ensure that our shared aspiration for long-term public access is grounded in law. Formal acknowledgement of this role also supports continued cooperation and collaboration with federal libraries and other agency partners. 
2.a. Make all information dissemination products managed by GPO available to collect and preserve.

Strengthening GPO's existing Chapter 41 mandate for an electronic storage facility, to indicate an access and preservation repository, would support continued development and maintenance of FDsys/govinfo. To fully achieve long-term access goals, this repository will require reliable funding along with appropriate staffing.

GPO currently manages content in its repository (FDsys/govinfo), on its servers ("permanent") and through vendors such as the Internet Archive. Content stored outside of FDsys/govinfo is typically made available on an accessonly basis, and at this time cannot be systematically accessed or collected for inclusion in a preservation system. The collection and description of these information dissemination products is already mandated as part of the Cataloging \& Indexing Program authorized in Chapter 17. To enable unmediated collection and preservation for libraries, this digital content should be ingested into FDsys/ govinfo. Doing so opens a pathway for public download, access, reuse, and preservation at a wide variety of scales.

2.b. Create a role for depository libraries to accept deposit of digital federal information.

Several libraries are already playing a role in preserving digital government information. Promising models are in place at a variety of scales, such as the system currently in use by Canadian libraries, and the distributed storage of FDsys/govinfo content in LOCKSSUSDOCS (see: https://lockss-usdocs .stanford.edu/) in cooperation with GPO. To improve coordination of this work and raise its profile, the FDLP should include an additional formal role for selective and regional depository libraries that are willing to receive and store digital government information on behalf of the program, and preserve and/ or provide access based on appropriate standards and agreements with GPO.

3. Improvements to broader federal information policy will facilitate better access and more reliable preservation.
Federal information cannot be preserved for future access if it cannot be collected. Greater agency cooperation with GPO is always desirable. However, absent a compliance scheme, incorporating principles of web design and structure that make agency websites and content easier to capture will enable better access and more reliable preservation. The Office of Management and Budget $(\mathrm{OMB})$ mandate to oversee federal information policy should extend to making executive agency and commission information dissemination products amenable to collection and preservation.

Information management is similar to any form of asset management: planning and documentation defines parameters, identifies benchmarks, and prepares the organization to manage obstacles. By creating public information management plans, agencies could document and communicate existing content lifecycles. Coordinating this work fits in the existing jurisdiction of OMB and could lead to improved business efficiencies within agencies. 